Article

\title{
Benches as Materialisations of (Active) Ageing in Public Space: First Steps towards a Praxeology of Space
}

\author{
Thibauld Moulaert ${ }^{1, *}$ and Anna Wanka ${ }^{2}$ \\ ${ }^{1}$ Laboratoire Pacte, CNRS UMR 5194/Université Grenoble Alpes, 38000 Grenoble, France; \\ E-Mail: thibauld.moulaert@umrpacte.fr \\ 2 Research Training Group "Doing Transitions”, Department for Social Pedagogy and Adult Education, Goethe University \\ Frankfurt on the Main, 60323 Frankfurt am Main, Germany; E-Mail: wanka@em.uni-frankfurt.de \\ * Corresponding author
}

Submitted: 7 February 2019 | Accepted: 16 May 2019 | Published: 18 June 2019

\begin{abstract}
In its promotion of "active ageing" through Age-Friendly Cities and Communities (AFCC) and the Global Network on AgeFriendly Cities and Communities (GNAFCC), the World Health Organization has developed a vision of ageing that links socio-spatial environments to personal lifestyles and community support. Approaching age-friendly environments from a "doing" perspective shifts our focus from such ideals to social practices, materialisations, and representations produced. Regularly referred to in AFCC discourse, public benches offer a great illustration for such materialisations. This article asks: what do benches tell us about the way ageing is framed and shaped in the AFCC discourse? How do benches themselves exhibit agency in it? Theoretically based on Lefebvrian social theory and critical gerontology, our reflexive article explores promotional/policy documents supporting AFCC worldwide, "good practices" shared by GNAFCC, and a series of European field observations around AFCC and benches and, finally, personal observations of ageing in public space around benches. Drawing on the Lefebvrian differentiation between representational benches, representations of benches, and social practices of benches, we show how benches can be considered as a socio-technical "assemblage" able to: 1) forge ambivalent representations and solutions for "active ageing" in public space, 2) illustrate, beyond the symbolic of space, the symbolic difficulties of "real" participative and multi-stakeholders governance promoted through "age-friendliness", and 3) explore everyday life practices of "spatial expulsion" of "ageing in public space" for older adults. In conclusion, we suggest a major shift for the AFCC program by finding inspiration in African practices of "ageing in public space".
\end{abstract}

\section{Keywords}

active ageing; age-friendly cities; critical gerontology; community life; environmental gerontology; public space; praxeology

\section{Issue}

This article is part of the issue "The City, Aging and Urban Planning", edited by Matthias Drilling (University of Applied Sciences and the Arts Northwestern Switzerland) and Fabian Neuhaus (University of Calgary, Canada).

(C) 2019 by the authors; licensee Cogitatio (Lisbon, Portugal). This article is licensed under a Creative Commons Attribution 4.0 International License (CC BY).

\section{Introduction}

Urbanisation and demographic change constitute two of the major developments of the 21st century. In 2014, $74 \%$ of Europe's population lived in urban areas (United Nations, Population Division, 2018), and by 2030, at least a quarter of that percentage will be aged 60 and over (Handler, 2014). Connecting these two global trends, the
World Health Organization (WHO) launched a number of policy initiatives based on promoting "age-friendly cities". These initiatives are based upon the WHO concept of "active ageing" as the core element (Buffel, Phillipson, \& Scharf, 2012). In 2005, the WHO initiated the "Global Age-Friendly Cities" project involving 33 cities, producing a "Global Age-Friendly Cities" guide (WHO, 2007a) that has been used as a flexible, yet in- 
fluential, checklist for policy-makers (Plouffe, Kalache, \& Voelcker, 2016), which contrasts with the critical interpretation of a "static" vision of age-friendliness (Keating, Eales, \& Phillips, 2013). While such checklists have been critically presented as an illustration of a "model of the 'ideal' city achieved through appropriate policy and service interventions" (Buffel et al., 2012, p. 598), Buffel and her colleagues call for "a focus on the material conditions of city life [as] a better starting point for understanding pressures on the lives of older people" (Buffel et al., 2012, p. 598).

Even though analysis of the literature suggests that the WHO's age-friendly cities framework is only one model that appears among a variety of potential ones (Lui, Everingham, Warburton, Cuthill, \& Bartlett, 2009), and even though it has been applied in different forms and with different foci (Moulaert \& Garon, 2016), the main idea of promoting active ageing through agefriendly environments and the general "age-friendliness" have spread across policies in various places in the world since the launch of the Global Network on Agefriendly Cities and Communities (GNAFCC) in 2010. Now, May 2019, with 847 individual cities and communities and 15 affiliate programs ${ }^{1}$, the GNAFCC is developed in 39 countries and, according to the WHO (2019), it covers "over 230 million people worldwide". Africa was the only region with no members in the GNAFCC. Two core elements of this program are: 1 ) the (call for) participative methodologies to collect voices of older people or to build bottom-up public policies, including urban planning policies, with older people, and 2) the promotion of a multi-stakeholder perspective beyond central ageing policy players. Officially, the WHO has now replaced "active ageing" with "healthy ageing" (WHO, 2015,2018 ) and targeted the promotion of individual "functional ability".

Adopting the "capability approach" of Amartya Sen, the organisation writes:

Functional ability comprises the health-related attributes that enable people to be and to do what they have reason to value. It is made up of the intrinsic capacity of the individual, relevant environmental characteristics and the interactions between the individual and these characteristics. (WHO, 2015, p. 28; emphasis added)

To reach it, the WHO nevertheless continues to mention "active ageing": "Healthy Ageing, like Active Ageing, emphasizes the need for action across multiple sectors, and enabling older people to remain a resource to their families, communities and economies" (WHO, 2019, p. 3). The shift confirms the locus on action, not only "cities" but "all sub-national levels of government, for any sector, public or private" (WHO, 2018, p. 3).
What does it mean, for an international organisation supporting public health, to come to the urban planning agenda? Is there any contradiction in promoting "active" and "healthy" ageing while, at the same time, supporting people in "being and doing what they have reason to value"? In the search for more "desired" ageing, does the WHO allow "mature subjects to develop multiple aspects of their experience that permit the emergence of life course-specific contributions to the wider social good?" (Moulaert \& Biggs, 2013) How far does the Age-Friendly Cities and Communities (AFCC) governance model permit such freedom of choice? How far does it contribute to a capability perspective (São José, Timonen, Amado, \& Santos, 2017)? Regarding the urban governance model promoted (one of multi-stakeholders, multi-levels, associated with a bottom-up perspective supporting "participation of older people"), does it support the democratic model (such as the "participative democracy" in France) by offering real power to older people? Or, on the contrary, does it offer new avenues for local players? Such questions can find an echo in the urban governance debate. "Classically, the literature on urban governance (or urban regimes or urban growth coalitions) aimed at pointing towards various mechanisms to create a collective capacity to go beyond market and state failures (Logan \& Molotch, 1987; Stone, 1989)" (Borraz \& Le Galès, 2010). Borraz and Le Galès conclude: "There is a good deal of urban governance going on in European cities but not all the time, not for all the groups, not for all the neighbourhoods and not so much for the peripheries of the city" (Borraz \& Le Galès, 2010).

This reflexive article is based upon longstanding observation of AFCC development in various parts of the world, including "champions" like the Quebec case, New York, or Manchester (Moulaert \& Garon, 2016); as researchers, we also participate in projects inspired by, and developed around, AFCC in Belgium (Houioux \& Moulaert, 2017) and Austria (Wanka et al., 2018). Regarding these experiences, we both notice a distinction between discourse and practices promoted; we also both notice, in terms of urban planning, (typically, the WHO refers to three domains for "physical environments": the built environment, transport, and housing) that benches have been regularly mentioned to illustrate action through "built environment" next to pavement attention or pedestrian crossing (WHO, 2007b). It, therefore, appears that "public benches" could be considered as a good socio-material disposal, a great "assemblage of human and non-human", assemblage being referred to by Deleuze and Guattari and to the ActorNetwork Theory (ANT) as "a mode of ordering heterogeneous entities so that they work together for a certain time". (Müller, 2015, p.28) To unfold such "assemblage", we propose a theoretical model of "ageing in public space" inspired by the three dimensions model of

\footnotetext{
1 "Affiliates are national or regional/state governments, civil society or research organizations, national or transnational city or community networks in WHO Member States that are working to promote age-friendly environments at the local, regional, national or international level" (WHO, 2019). Such affiliates can be very large, like the Quebec Province, which includes more than 899 municipalities.
} 
space by Lefebvre (Lefebvre, 1991) and by a "doing" perspective on ageing (Wanka et al., 2018). Such a model has already been tested (Moulaert, Wanka, \& Drilling, 2018) to discuss the level of internationalisation of the general framework of ageing and social exclusion (Walsh, Scharf, \& Keating, 2017) and to propose a theoretical advance in "environmental gerontology" from "environmental press to spatial expulsion" (Wanka, Moulaert, \& Drilling, 2019). Here, its use is suggested in order to consider public benches as the "usual suspect" to connect the various (and potentially contradictory) conceptions of ageing in public space emerging through urban research and policies governance supported by the GNAFCC.

\section{Methodology}

This article is reflexive. The first part of the empirical material has originally been collected as intuitive materials: here, we collect the WHO global documents explaining the AFCC framework: the 2007 guide (WHO, 2007a), its checklist (WHO, 2007b; see Figure 2); AFCC guide from affiliate programs from Quebec (Équipe de Recherche MADA Québec \& Carrefour Action Municipale et Famille, 2013) and from France (Giacomini \& Lefebvre, 2019; Lefebvre \& Chapon, 2014), and documents from "champion cities" like New York (Finkelstein, Garcia, Netherland, \& Walker, 2008) and Manchester (Buffel, 2015; Manchester City Council, 2009), these last cities having included a Master thesis on benches (Barron, 2015). These cities are considered "leaders" because they are both strongly connected with the historical development of GNAFCC; New York city was member of the 33 cities at the beginning of the program (WHO, 2007a) and Agefriendly New York city was awarded "Best Existing Agefriendly Initiative in the World" in 2013 by the International Federation on Ageing. Manchester was initially absent from the first WHO study. However, it has rapidly become a visible city at the European level, with its image and practices circulating in transnational spheres. Manchester has been cited in European areas as well as in the Organisation for Economic Co-operation and Development report (OECD, 2015). In all these documents, we isolated the images and references on "public benches".

To complete this first "grey literature", we explore the "Global Database of Age-friendly Practices" (https://extranet.who.int/agefriendlyworld/afp) by selecting actions under the proposed category of "urban development" (26 "practices" were isolated) and under the proposed category "be mobile" of "desired outcome for older people" (27 "practices" were isolated). In each of these two categories, we find the same 5 cases of "benches", 4 of them being clearly centred on "bench and seat", one being indirectly concerned with benches as part of park planning (see Appendix). All "proposed categories" came from GNAFCC website. ${ }^{2}$ This database is built to present inspiring practices on AFCC and, therefore, the cases can be seen as "good examples" to be shared.

Lastly, we compare the ethnographic observation of bench installation and use in Vienna, Austria, and in a French city close to Grenoble (it includes 5 interviews with older people walking outside). Here, the material explores the dissemination of benches and how older people are using them or not.

\section{Exploring the Complexity of "Ageing in Public Space": Henri Lefebvre's Tryptic and the Search for Praxeology of Space}

The work of Henri Lefebvre (1991) is especially valuable for our understanding and may be used not only as a general justification to support the "right to the city" of older people (Buffel et al., 2012). Lefebvre introduces his understanding of the production of space early on in his theory of urban development, from which further fundamental urban research work has benefited. According to Lefebvre, place is a product of the dynamic between everyday practices and perceptions of people (spatial practice), cognitive concepts or theories of space (representational space), and the spatial imaginary (representations of space; Lefebvre, 1991):

- Spatial practice refers to the everyday practices and perceptions with which ordinary people encounter and use space. It comprises the daily routines and paths older people follow within their scope of action, the places they avoid, and the ways they appropriate places and attach a feeling of home to them.

- Representational space refers to the passively, instead of actively (see above), experienced spacethe way people subconsciously read and understand signs and symbols in space. These symbols help us to distinguish a road from a sidewalk or a playground from a park, but they also give us clues on where to go and where not to go, for example via signs of disorder that might symbolise crime in a certain area (cf. Kelling and Wilson's broken windows hypothesis). Hence, representational space and spatial practice are closely related.

- Representations of space are the conceptualisations of space made by planners, scientists, and policy stakeholders. The representations may manifest materially in the form of maps, plans, models, and designs. Such representations are laden with ideologies and have a substantial role and specific influence in the production of space. Regarding ageing, concepts of age-friendly cities would constitute a very clear case of the representations of space.

\footnotetext{
2 Surprisingly, the website even presents around 10 practices from 1974 to 2001 . As we know, "active ageing" has only been promoted since 2002 by the WHO, so what does such "ghost" actions mean? They might illustrate the capacity of local stakeholders to present existing practices as "innovations".
} 
We suggest that such concepts would assist in offering a deeper understanding of the experiences of everyday life of place (spatial practice) in relation to public policies (which are influenced by representations of space such as AFCC). It might also be a starting point for conceptualising new solutions for the challenges of "ageing in public space", including social exclusion (spaces of representation). Nevertheless, the historical Marxist perspective of Lefebvre also means that his triad insists on power circulation. In critical urban research, urban development is understood as being the result of actions and decisions made by different powerful stakeholders. Social, economic, physical, as well as spatial structures of neighbourhoods and cities are understood as being in constant change and producing relational spatial structures, which in theories of urban development are often referred to as "social space" or "practice of everyday life" (de Certeau, 1984; Sennett, 1999). Such spaces are understood as being the result not only of human actions, but also as mirroring social relations and being influenced by the wide scope of human action. Power relations refer to the structural and political dimensions of space.

Following this perspective, Lefebvre's theory suggests what social sciences call a "doing" perspective or praxeological on space. This means space is nothing as static, pre-existent, or equivalent as a container; instead, it is something that is continuously produced and reproduced through social practices (Butler, 2004; Löw, 2008). What constitutes social space is the human activity that takes place in it. The philosopher and social geographer Ted Schatzki (1991), for example, gives an early practicetheoretical account of the construction of space through practices. He claims that "human agency is inherently spatial" (Schatzki, 1991, p. 651), that social practices are hence inherently spatial phenomena and that space is an inherently praxeological matter. Social space is a space to do something: a park is linked to a different set of deployable practices than a street, playground, beach, etc. And a bench is, consequently, linked to specific sets of practices, like resting. Reckwitz (2012) goes as far as to claim that social practices form the "missing" link urban sociology has been searching for, namely by preventing the scientist from leaning either towards "the objectivism of the present container model or towards the subjectivism of a purely experiential or imagined space":

When social practices as on-going activities drag bodies and artefacts with them, they always necessarily "spatialise", meaning they produce their respective spaces as three-dimensional arrangements comprising artefacts and bodies. (Reckwitz, 2012, p. 252)

Space is, thus, something that is both constituted by practices and defines the range of practices that are appropriated to deploy within it (comparable to Goffman's concept of behaviour setting). Although a bench is linked to practices of resting, for example, sleeping on benches in public spaces may be stigmatised, and increasingly prohibited through specific design elements.

Different complexes of social practices co-produce spaces, and some of these complexes are more powerful than others. For example, urban planning practices or practices of house selling or renting might play a more significant part in spatial segregation (as spatialised inequalities) than practices of everyday appropriation. Yet, being embedded into a fabric of other social practices, urban planning practices alone can never determine the production of spaces-what in the end defines them is their actual everyday use. Thus, a praxeological or "doing" approach towards conceptualising space is neither in favour of determinist, functionalist, or topdown approaches, nor is it in favour of completely participatory, bottom-up approaches. It will be illustrated by the tension between the top-down vision of benches in AFCC ( $a$ bench to rest) and practices of benches explored through participative approaches (when older people participate, they share other senses then resting, such as "going out" from home).

In the following section, we use the assemblage of "public benches" to analyse the "structural and political dimension of space" in the new "active and healthy ageing" WHO agenda through the lens of social practices and their materiality. "Assemblage" is the translation of the French "agencement" defined by Deleuze and Guattari in Mille Plateaux. Referring to this origin, Müller identifies 5 features. First, "assemblages are relational. They are arrangements of different entities linked together to form" (Müller, 2015, p. 28). In contrast with ANT, an assemblage is composed of relations of exteriority, meaning that the explanation of the relations is never (only) situated in the components or entities. Second, "assemblages are productive". This strongly applies to our search for a praxeology of space and suggests some contradictions with our Lefebvrian tool and its importance of representations. Third, "assemblage is heterogeneous", composed, like ANT, of diverse entities, humans and non-humans. Fourth, and deeply shaped by Deleuze and Guattari, "assemblage is caught up in a dynamic of deterritorialisation and reterritorialisation" (Müller, 2015, p. 29), best illustrated by the importance of "wind and epidemics" in place of "heredity, alliance" in their philosophical perspective. Fifth, "assemblages are desired", referring to their corporeal component. In short, "assemblage" is a tool to follow the multidimensional perspective of space opened by Lefebvre and to adapt it towards the exploration of a new praxeology of ageing in public space.

\section{Public Benches as an Assemblage of "Ageing in Public Space"}

Applying the three dimensions of space together, we show how the assemblage of public benches in AFCC: 1) it forges ambivalent representations and solutions for "active ageing" in public space, 2) it illustrates, be- 
yond the symbolic of space (benches as a relaxing place), the symbolic difficulties of "real" participative and multi-stakeholders governance promoted through "age-friendliness" and, 3) explores everyday life practices of "spatial expulsion" of "ageing in public space" for older adults.

\subsection{Representation of Space: Public Benches as a Passive Resting Place or as an Active Stop-and-Go Place?}

Clearly, the idea of benches as a place to rest has been a highly-visible but apparently invisible aspect of the more-than-often cited guide on AFC (WHO, 2007a). It is replicated for example in the first French guide (Lefebvre \& Chapon, 2014; see Figure 1) and occupied a very good position (second) in the associated checklist (WHO, 2007b; see Figure 2).

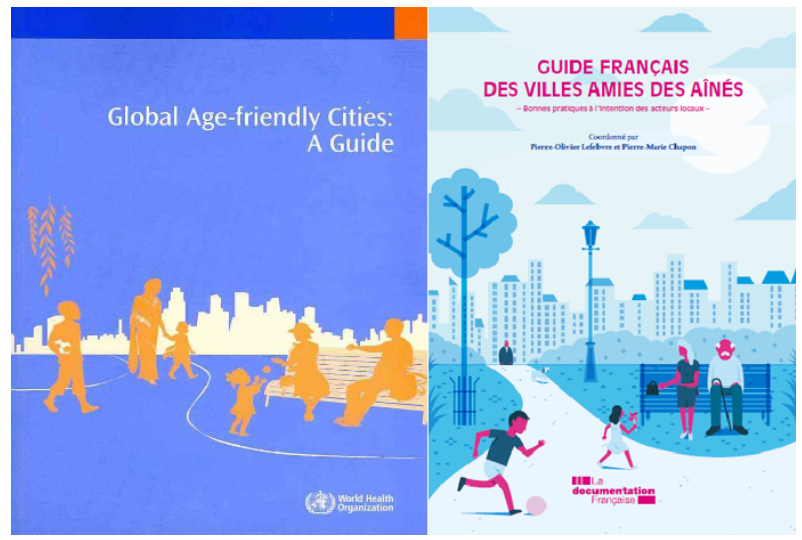

Figure 1. Cover to Global Age-Friendly Cities: A Guide (WHO, 2007a) and Cover to the Guide Français VADA (Lefebvre \& Chapon, 2014).
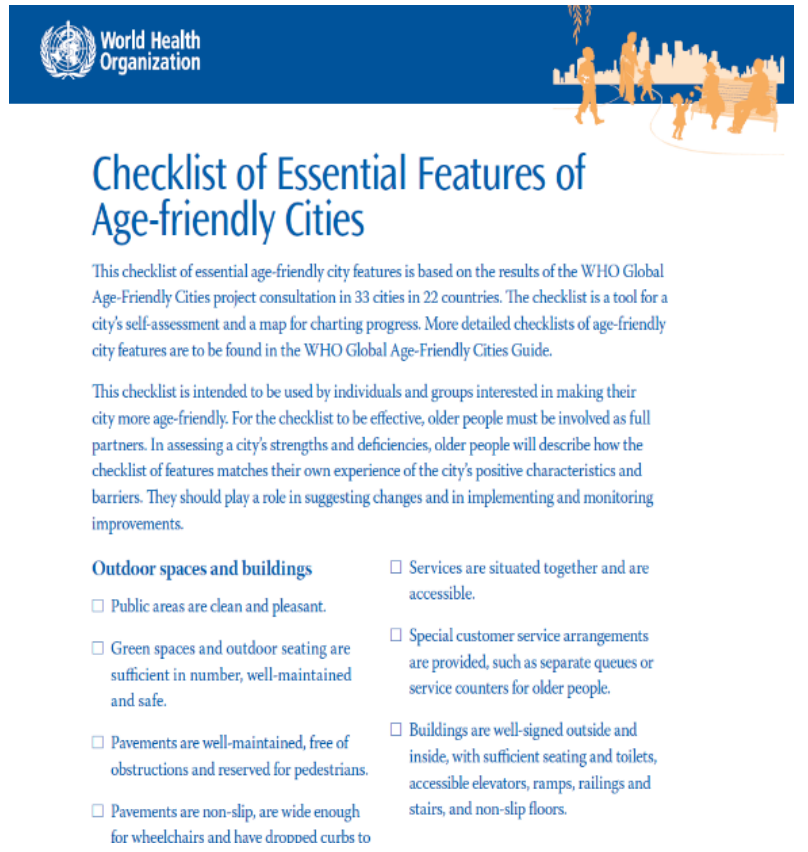

Figure 2. Checklist (WHO, 2007b).
In gerontology, one of the fathers of activity theory supporting "active ageing" illustrates the need for "role flexibility" for retired people. Interestingly enough, the romantic idea of "sitting on a park bench", as expressed by the covers mentioned, was already there:

Consider the changes in the role which may be made by a man just before and after age 65 when he was automatically retired from his work.... He may spend more time with friends at his club; indeed, he may join a club for this very purpose. He may use a park for the same ends, sitting on a park bench with others in pleasant weather, or lounging in a park building when it is wet or cold. (Havighurst, 1954, p. 310)

New York has been particularly active in promoting the installation of benches. Interestingly, the program defines priority location for bench installation, including classical gerontological sites like hospitals and community centres, but also places of consumption (commercial zones) and public facilities (public libraries). In so doing, benches might not only be considered as a "passive place" to sit and relax but as a "stop and go" object to support active engagement in city life, including access to public transport and, at least in New York city, consumption. The CityBench program is one of the key initiatives of New York city to increase walkability:

Through a federal grant, the Department of Transportation (DOT) is installing 1,500 attractive and durable benches around the city, particularly near senior centres and housing; hospitals and community health centres; commercial zones and shopping districts; and municipal facilities (e.g., public libraries, schools). Individuals and communities can request a bench in a specific location, and older people report having made new social ties with people who frequent the same benches at the same times....Finally, in response to feedback from older people that bus shelters often lacked seating and felt unsafe, 4,000 new bus shelters have been installed. The new shelters have seating and the walls are transparent, addressing concerns about the old shelters which hid their interiors from view. These shelters are paid for by advertisements projected on their sides. DOT has replaced almost every pre-existing bus shelter and has installed additional bus shelters at locations throughout the five boroughs identified by older people and community leaders. (Goldman, Owusu, Smith, Martens, \& Lynch, 2016, p. 178)

Similarly to any AFCC practice, the benches meet a problem. How can we evaluate their uses? How can it contribute to "active and healthy ageing"?

While some interventions yield tangible results, such as a reduction in senior pedestrian fatalities or increased strength resulting from an exercise program, 
others are not so easily quantified, such as the overall impact of a bench. (Goldman et al., 2016, p. 187)

To consider "public benches" as "assemblage" according to classical ANT, representations of space need to "take place" in maps, graphs, tables, and figures. In AFCC, this could happen with a mapping exercise. Such maps can be used by city planners who organise participative walking methodologies (like in Rennes, case 1, in Appendix) or like in Manchester to grasp the variability of practices (see Section 4.3): "A variety of seating should be installed, based on work with older people, using recommendations from 'Design for Access 2' as a benchmark of good practice" (Barron, 2015, p. 3).

We applied a similar practice (outside of an AFCC program) to prepare ethnographic observation of a large neighbourhood, with a high rate of $60+$ inhabitants (the municipality has a higher rate of older inhabitants, $19 \%$ of $60-74$ years and $11 \%$ of $75+$ years, in comparison with $14 \%$ and $8 \%$ in the Department; in the studied neighbourhood, the rate of $60+$ increased by $2.3 \%$ from 2007 to 2012) in a relatively well-off city close to Grenoble (France). We organise a similar mapping exercise with students. Figures 3 and 4 illustrate a section of this neighbourhood. Even at the neighbourhood level, we can easily observe a very different repartition of benches in public space, sector 1 being largely equipped, while sector 2 is equipped with gathered benches.

From this "mapping exercise", a concentration on benches clearly appears in front of shops, restaurant, and public services (post office and pharmacy); a second concentration of benches is in a small garden, circled by residential building towers. Benches are old and the playground seems abandoned. Such observations raise the question: are benches only made for sitting? What are their symbolic dimensions?

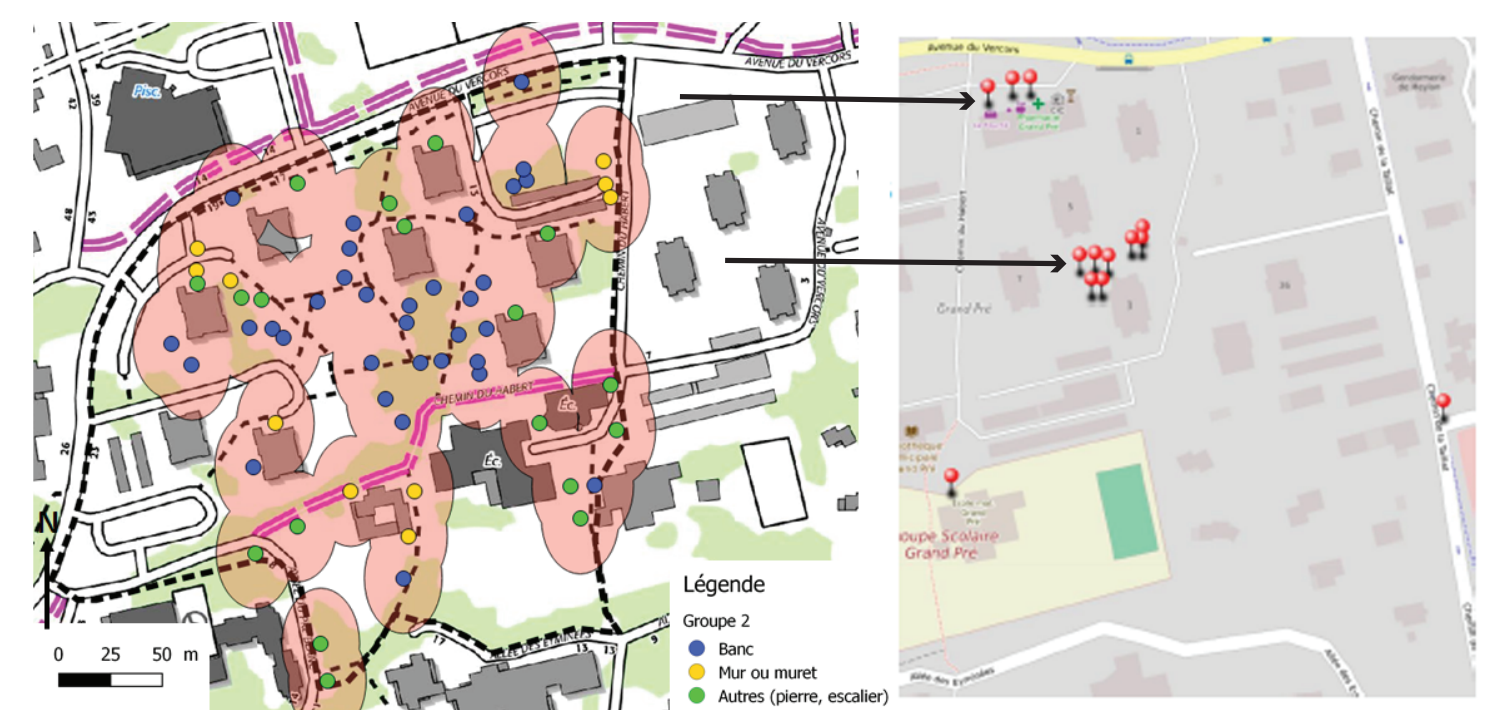

Figure 3. A French neighbourhood with benches, sector 1, on left (blue spots); sector 2, on right, with 2 concentrations of benches (red points).

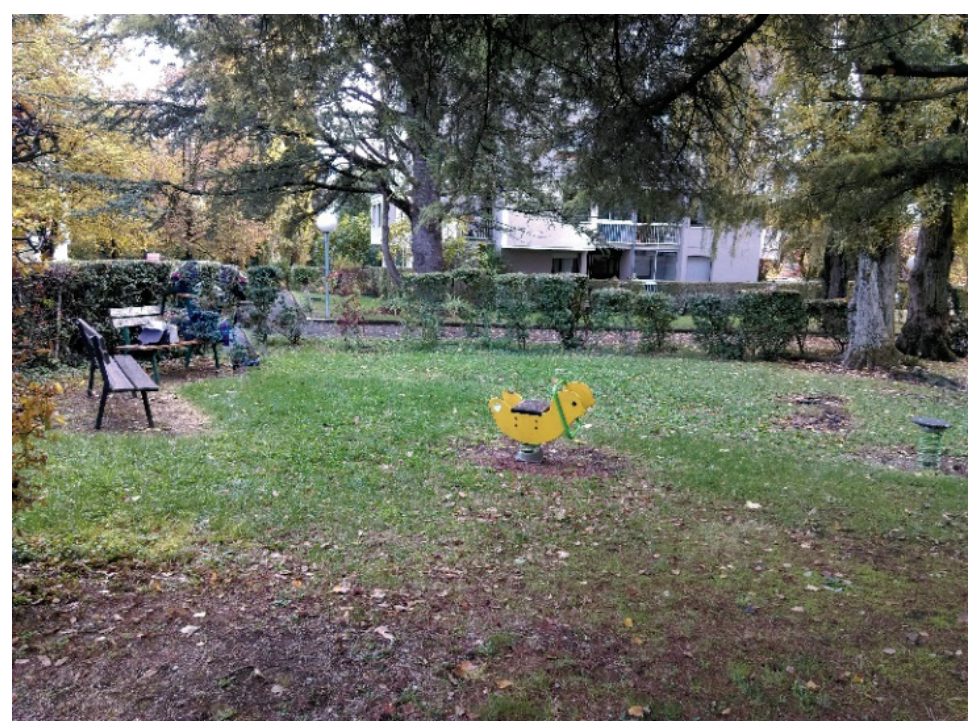

Figure 4. The picture of playgrounds with benches of sector 2 (picture by student A. Lemarchand). 
4.2. Representational Space: Public Benches as a Symbol of Relaxing and Democratic Participation?

Like plenty of illustrations of benches in municipality reports (see Figure 5), or in the cover of the WHO Guide of 2007 (see Figure 1), the benches offer an implicit meaning of relaxing. Figure 5 illustrates 2 people sitting in a sunny environment. Relaxing comes with discussing together, laughing together, when two or more people are presented. However, benches are never illustrated with people sleeping or drinking on them, even if the definition of "active ageing" might be scrutinised and enlarged toward such domains as explored in playing billiards (Lassen, 2015). It is not to say that benches cannot serve such purposes. It is suggested that, through AFCC discourses and representations, benches "should be used" for relaxing and thus "should" exclude other symbols.

Indeed, any conception of benches also reveals a more or less implicit political narrative. For example, armrests might be presented as a useful aspect of benches for older people and other populations to stand up after being seated. It eventually has an esthetical aspect (see Figure 5) which makes the physical environmental welcoming. However, armrests can also be used to assume a symbolic selection of accepted people in public place. The well-known "anti-homeless benches" (see Figure 6) are a clear illustration here. However, the armchairs in Figure 6 can play such an implicit role, excluding homeless persons and supporting people with difficulties to stand up. Such excluding symbols are never illustrated in any AFCC documents we observe and it never officially appears.

A second symbolic dimension inhabits the public benches; however, it is less the symbol of place itself which is discussed. It is the process of bench installation that is symbolic. While a strong participatory perspective is announced in AFCC in general, research has shown that such an urban governance model is rarely effective (Buffel, 2019). The "participative level" is regularly reduced to "consultation" of older people, like in the seminal Vancouver Protocol (WHO, 2007a) and in the first times of AFCC development in France (Lefebvre \& Chapon, 2014); through the WHO call for more participative practice from its affiliate members, the French methodology insists officially more on "social participation" of older people not only through consultation but also inclusion of "older citizens" in the steering committee (Giacomini \& Lefebvre, 2019) following
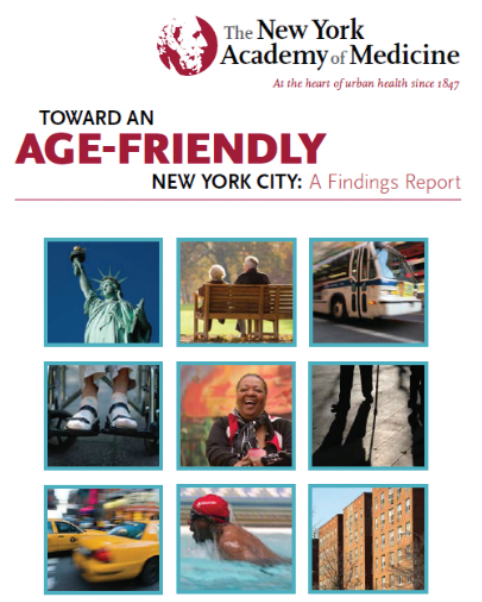

Fall 2008

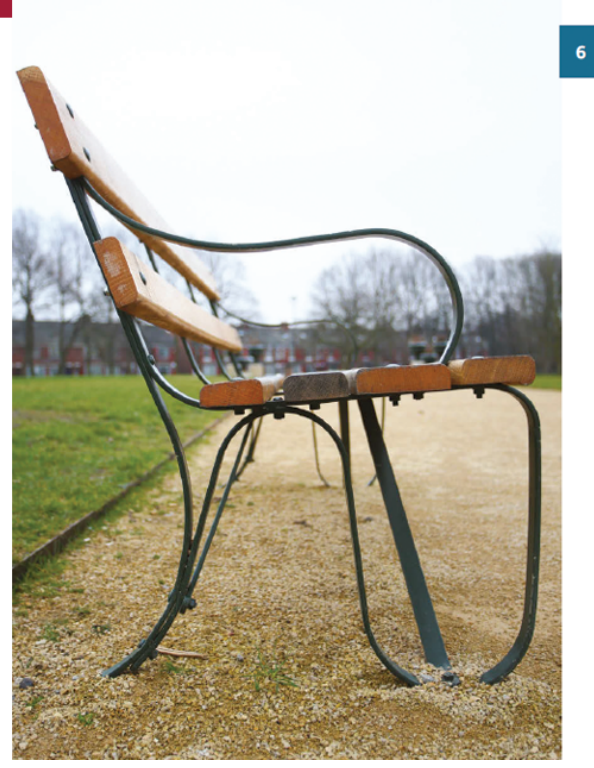

KEY FINDINGS FROM THE PROJECT ACCORDING TO THE CO-RESEARCHERS

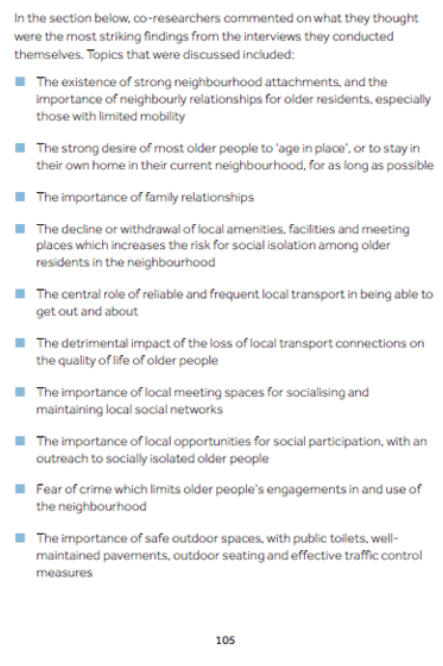

Figure 5. Cover of a New York city report supporting NYC AFCC (left; Finkelstein et al., 2008); inside pages of Manchester AFCC (right; Buffel, 2015).

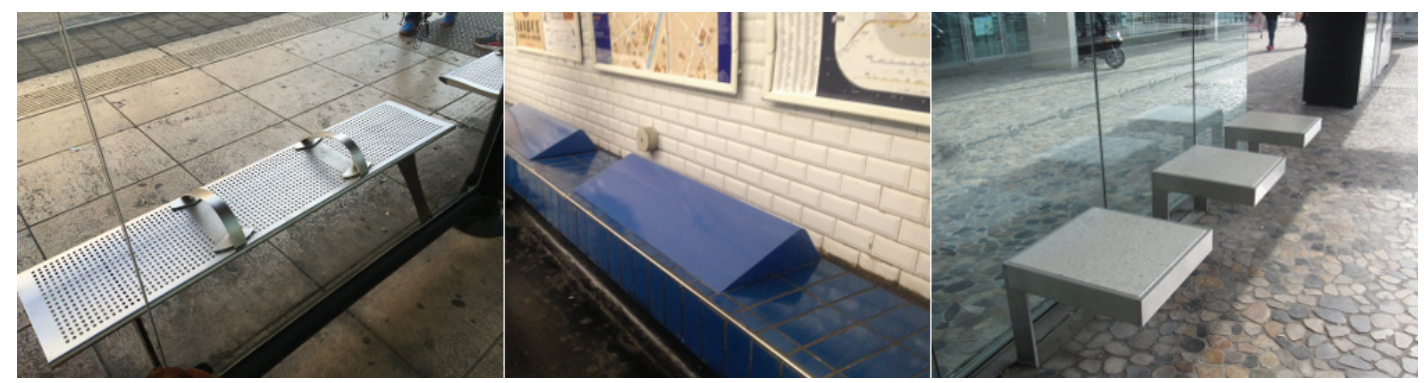

Figure 6. Examples of anti-homeless benches in Stalingrad Station, Paris Metro and bus shelters. Source: the authors. 
the Québécois framework (Équipe de Recherche MADA Québec \& Carrefour Action Municipale et Famille, 2013).

However, until now, there have been no qualitative data "proving" the level of older people participating in such a steering committee. Researchers supporting such a participative agenda are working with the idea that such participation "changes something". However, there is no proof. On the contrary, the case of "bench discussion" is a pragmatic case to assess the potential or real role of older people.

We first go back to the CityBench program in New York city. While huge numbers of benches have been installed, and while a real participative methodology has been supported to follow older people's choices, it nevertheless appears that only $10 \%$ of installations have been produced from this source. Decisions regarding space still appear as a central decision made by planning experts:

As of the end of May 2013, 536 benches had been installed (173 at bus stops), 68 benches had been installed at the request of senior centres, and more than 50 benches had been placed in locations requested by Aging Improvement Districts, the Age-friendly NYC neighbourhood level community organizing initiative. (New York City Office of the Mayor, 2013, p. 12)

We secondly observe that such governance gives a special place to "intermediaries of active ageing", defined following ANT's inspiration, as people or processes organised to connect ideas and practices, to create awareness among various stakeholders around active ageing (Moulaert \& Houioux, 2016). In selected cases of bench installation (see Appendix), municipal employees often appear as key players. They can organise a walking methodology, promote participation by including the voice and presence of older people (like in Figure 8) and, from time to time, elected politicians or Mayors (like in Figure 7). In Rennes (see Appendix), the explanation of the case mentioned that the challenge was to make connections between municipality services, which is a recurrent aspect of inter-sectoral governance of AFCC.

In Kwai Tsing (see Appendix), some older people are described as "the age-friendly ambassadors" who may play such a connecting role when they "should bear these [physical constraints for the location of the benches, such as narrow pavement or the presence of footpaths were challenges during the project] in mind when proposing suitable locations for such works" (WHO, Global Database of Age-friendly Practices, n.d.).

The journey of bench installation for seniors can illustrate the various roles that such professionals (and here we do not consider the "age-friendly ambassador") can play: when playing a role of intermediation, the agents act as facilitators and carefully link all of the players with the seniors on one side and politicians on the other. Drawing on their professional or personal experience, they seek to operationalise the public action desired by

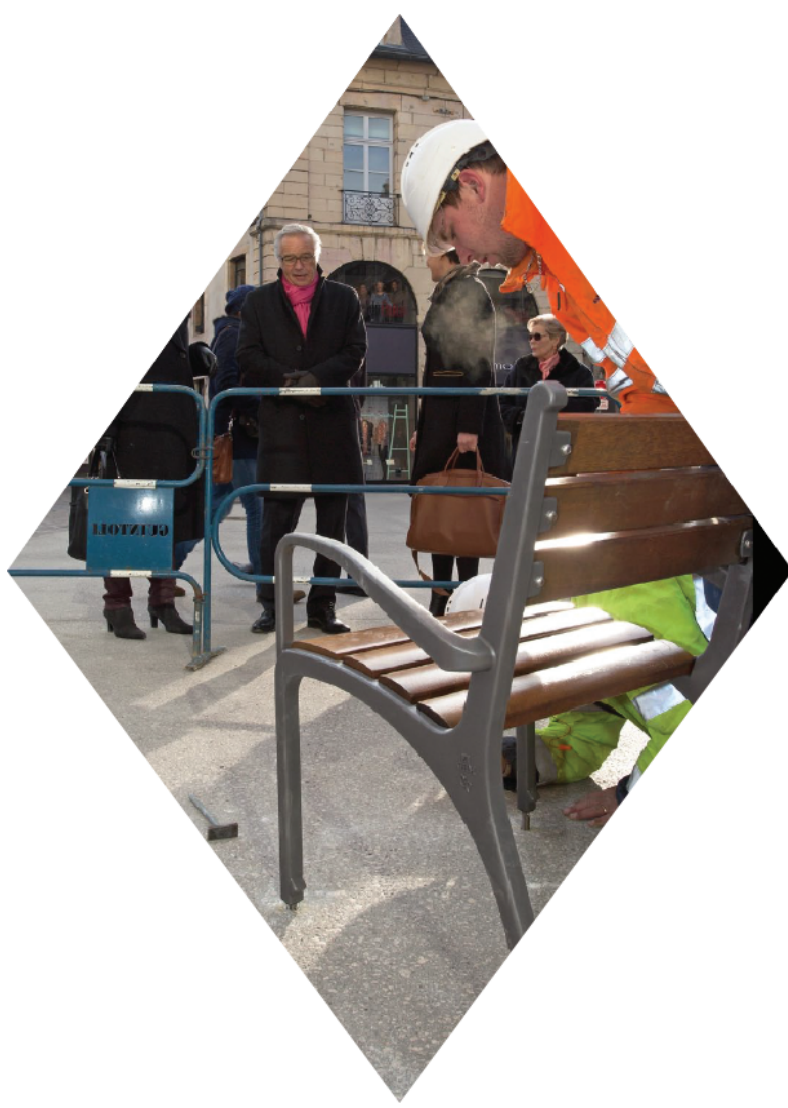

Figure 7. Installation of a bench under the supervision of a Mayor. The promotional document here refers to "A participatory democracy challenge". Source : Lefebvre and Chapon (2014, p. 38).

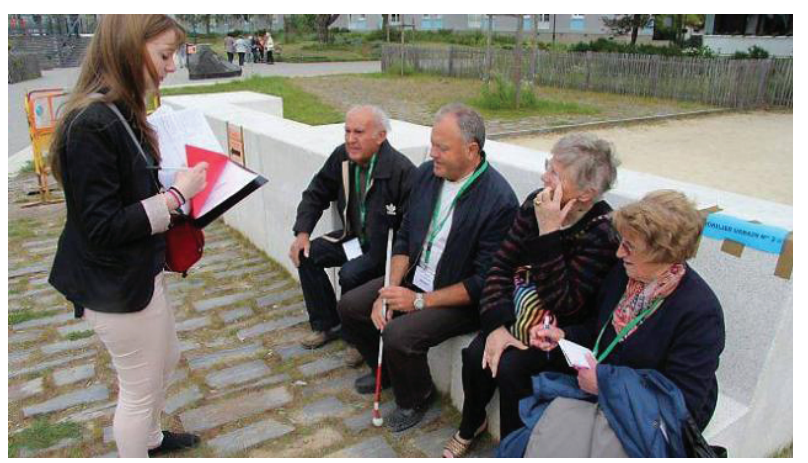

Figure 8. Public benches tested by inhabitants. Source: Ouest-France (2015).

the first and decided by the latter. In the different situations encountered in Belgium, the choice of benches is an exemplary case. When the demand for benches is locally emerging, it is administrative staff members who identify the different types of benches. Later in the project, the negotiation of the location of benches is done in collaboration with seniors, based on their lived experience of territorial space and neighbourhood. In the end, the symbolic call for a participative governance of the city, including older people, appear distributed through such intermediaries. 


\subsection{Towards the "Spatial Expulsion" of Ageing in Public Space?}

This last section explores what has been termed "spatial expulsion" (Wanka et al., 2019). How do benches participate in such a process?

In France, with a group of (6 young) students, we decided to walk around the selected neighbourhood (see Figures 3 and 4) and to sit and wait on benches. Due to bad timing (observations took place in October and November, one on a sunny afternoon, the other in much colder conditions), the number of sitting older people were close to zero. However, we observed a series of (older) people walking into the neighbourhood. Two months later, we went back and had 5 qualitative interviews with older people walking outside. Our experience indicates an apparent contradiction: a lot of benches are situated in the neighbourhood, but there is little information concerning their use.

During the fieldwork, we note 3 elements. First, when meeting a group of 2 youths, they mention: "Yes, older people are everywhere here". "Here" probably means "inside" houses. "Outside" public space seems "older-people-less". At least at this time of the year. Second, even if very few people apparently use the many benches, sitting on benches is a good observatory to note the walks of certain types of people. In particular, due to the residential nature of the neighbourhood, older and younger people and kids walk together, the latter coming back from school; other couples also consist of a very old senior walking with a younger person (his son?). Third, a lady, living in residential home care for autonomous persons, explained to us how she used to walk from her housing towards the shops (around 200/300m far). She clearly identified one bench on her trip and explained that this bench is essential to her because it has armrests Other benches (Figure 9), even if closer from her place and well-situated (with a nice view of the mountains), are not perceived as "useful" because they are not on the way and because of not having armrests Other interviews inform us about the similar "habits" where space produces a relative practice of public space supporting a feeling of "spatial expulsion". In contrast, "home" becomes "the place to live older". And "home" can be disturbed by public place. Indeed, the bench can even become problematic when its use is supported by "unpleasant occupants". In his interview, an older neighbour clearly states:

Yes, we had a bench down from our building. And a guy was playing the guitar, drinking all night and he was screaming every night! My son wakes up at 4 for work....So, one morning, we were so upset that we removed the bench!

Indeed, benches are not always used by older (or younger) people for resting. In non-participant observations in Vienna, Austria, we also observed a group of older men who were daily visitors. Moreover, they 'monopolised' a set of benches on which major parts of their social life would take place. They were playing chess and drinking beer on those benches, squeezing the empty cans between the wooden beams so the wind wouldn't carry them away. Other older men and women would walk by, greet each other and have a chat, and sometimes the men would offer them a place on their benches, moving closer together to allow sometimes ten people to sit on two benches made for four. Even when the group was not present, 'their' benches would not be used by any other visitors to the park.

So the final question is: what makes people DESIRE to go out and sit in a public space? It interestingly comes back to the original motto of the WHO:

Functional ability comprises the health-related attributes that enable people to be and to do what they have reason to value. It is made up of the intrinsic capacity of the individual, relevant environmental characteristics and the interactions between the individual and these characteristics. (WHO, 2015, p. 28; emphasis added)

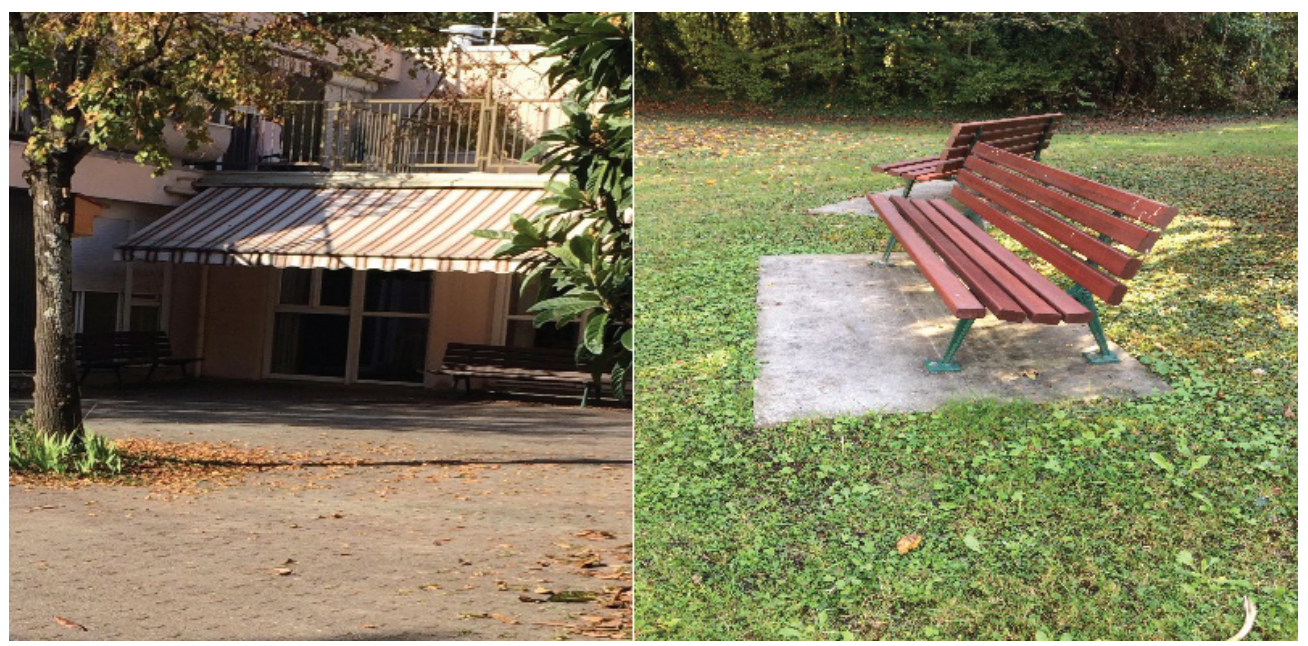

Figure 9. Benches in the studied neighbourhood. Source: the authors. 


\section{Discussion}

This article raises the question of what benches tell us about how ageing is framed and shaped by the AFCC discourse and practices. The "assemblage" of public benches is made of: 1) ambivalent representations and solutions for "active ageing" from "passive" sitting and relaxing representation to an alternative "active" stopand-go scripted practice, 2) it also comes with diverse symbols, from the "resting and relaxing" space to forms of disseminated "social participation" urban governance shared with older people and intermediaries of "active ageing", and 3) finally, it explores forms of "spatial expulsion" from space that could involve older people, directed towards their inner home, but also expel other public from space if they are considered as "unpleasant occupants".

These three dimensions explore the composition of a heterogeneous "assemblage" shaped by the Lefebvrian triptych in a very "top-down" perspective, from central WHO ideas to the local experiences of places. Contradictions arise at different levels and political dimensions of space are salient. For example, the unsolved tension between active/passive ageing is strongly rooted in the "representation of space" with benches. While not completely resolved with the next dimension, the "representational space" and the symbolic space, this nevertheless offers some clarification (clearly related to the "relational" aspect of "assemblage" and the need to connect its components with the external world). Here, the political dimension of benches means that benches are a space for democratic participation regulation: even if we only point to the positions of older people, elected officials like mayors and of "intermediaries of active ageing", this avenue might probably include more actors like private providers of benches and other urban furniture. Lastly, the third dimension explored the "social practice" of Lefebvre. While the power relation to space is essential in Lefebvre's perspective, our first exploration suggests that older people do not deeply benefit from public space and that benches can help to delay their expulsion from it. However, such benches are part of learned habits and practices of space. In terms of urban planning (and to the two other dimensions proposed by Lefebvre), there is no evidence that the installation of new benches could change such practices.

However, as presented in the theoretical section, a praxeological or "doing" approach towards conceptualising space is neither in favour of determinist, functionalist, or top-down approaches, nor is it in favour of completely participatory, bottom-up approaches. This twosidedness could be even clearer with a last example. Imagine the old woman on the park bench again. What constitutes the park as a park are the planning practices that laid it out in a certain way, including lawns and paths, benches and maybe a playground; it is the practices that built it and maintain its looks and it is the practices, like that of the old lady reading her newspaper, that actualise its existence as a park. That particular park bench where she is sitting continues to be perceived as a park bench because she is sitting there. If it was, for example, used to deposit garbage, it would physically still stay a park bench, but it would start to be perceived as a garbage disposal. Conversely, people are usually more likely to use a bench for sitting than for depositing garbage, using it for skateboard stunts, or to do Yoga. Schatzki (1991) speaks in this regard of spatial action governing factors (e.g., ideas, emotions, knowledge, customs, etc.), practical skills, features of the world (e.g., possible uses of objects by the way they are designed), and space-time packing constraints that are all facilitating practices. The space, thus, shapes practices in the sense that: 1) it limits the possible practice scope, and 2) it influences how practices are carried out. Walking on a slippery road, for example, is performed differently from walking on a firm base; walking on a street without bathrooms is also performed differently than walking the same street with bathrooms. Regarding this last element, while the material world is similar, its political economy varies from a public-supported version in the French model of AFCC (Giacomini \& Lefebvre, 2019) to a private-supported version like in the "expert's discourse" in New York city: "Lack of public bathrooms throughout the City was also frequently mentioned; experts suggest providing incentives to local businesses that open their facilities to the public" (Finkelstein et al., 2008, p. 40).

In order to fully complete such a praxeological perspective, the next research steps could focus only on bench use, away from any AFCC program. Another research avenue remains connected with the GNAFCC. It critically discusses the hegemonic "North" vision developed until now by such a network. Such an avenue is explored in the conclusion.

\section{Conclusion}

This article describes the "assemblage" of "ageing in public space" through the lens of public benches promoted by GNAFCC worldwide. In conclusion, we would insist on the very problematic democratic issue inside AFCC urban governance. Back to the quotation of Borraz and Le Galès (2010), we can agree that "there is a good deal of urban governance going on in European cities but not all the time, not for all the groups, not for all the neighbourhoods and not so much for the peripheries of the city". Excepting the "inner city/periphery" dichotomy on which we do not have sources in AFCC, it is obvious that in each AFCC practice, "not all the time", "not for all the groups" of older people and not in "all the neighbourhoods", do AFCC discourses have a similar impact or a similar aptitude to deeply involve older people in local governance. However, one solution could be to extract ourselves from a pure "North" vision and try to learn from the "Global South".

Today, the majority of actions from GNAFCC are situated in Europe, America, and the Western Pacific. The 

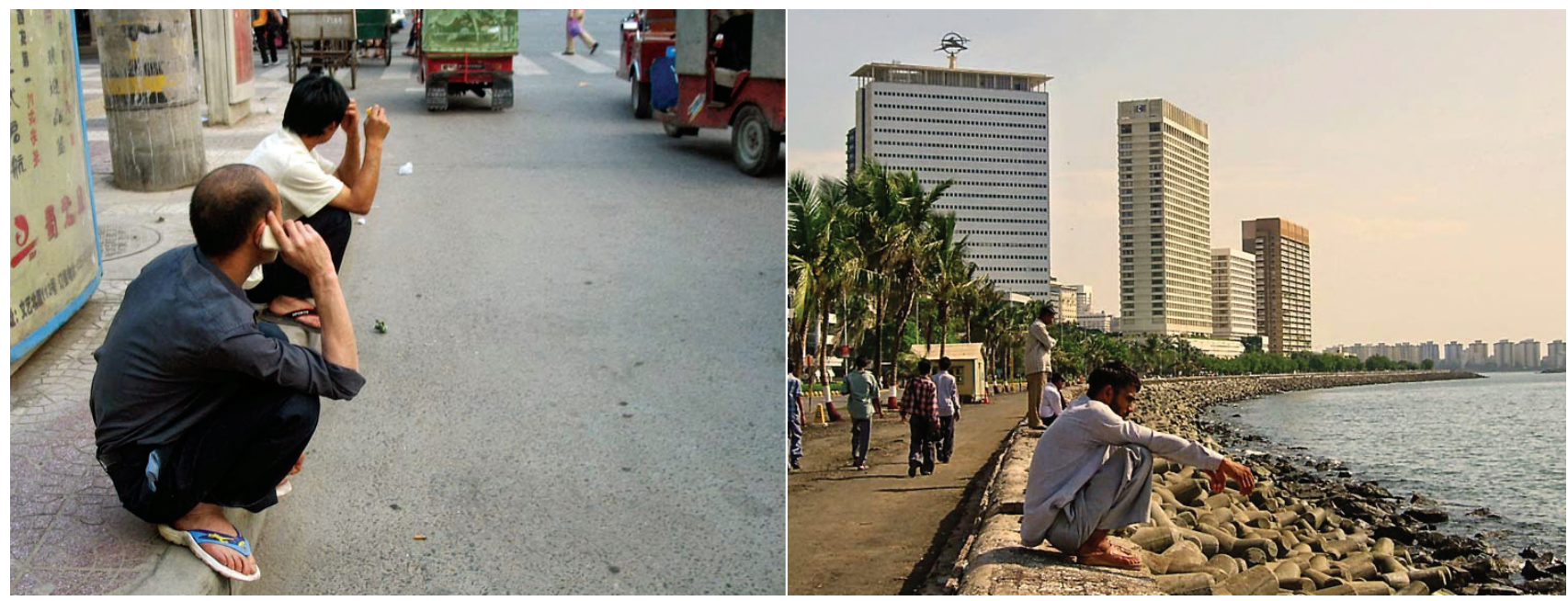

Figure 10. People sitting on one's haunches as common practice. Source: Stock Pictures (2014).

absence of any African case has already been discussed as one of the great imbalances between the Global North/South of the Network (Moulaert \& Garon, 2016, p. 14); it has only recently been admitted (WHO, 2018). Can we consider how benches might provide a link between Global North and South?

As mentioned above, no African city is yet part of the GNAFCC, but there are some African countries reporting national programmes on age-friendly environments (WHO, 2018). While many African cities still face significant challenges to become age-friendly, the provision of benches doesn't seem to be one of them. While there are urban parks designed with Western ideas in mind, the livelier places are often more informal. In these places, everything can become a makeshift bench or chair-bus stops, spaces in front of little shops or highways. From a "doing" perspective, every material that is used as a bench becomes a bench-may it be just some stones, pieces of wood, a ladder or a car tyre. Such materials might only become benches for a short time and might be used for something else the next minute. Furthermore, we might also observe China and India, where sitting on one's haunches is still common, particularly for the poor population (see Figure 10).

From the strengths of such informalisation arose the term of 'African Urbanism' or 'Southern Urbanism'. Schindler (2017), for example, defines three tendencies of this kind of urbanism(s): 1) persistent disconnect between capital and labour, which gives rise to urban governance regimes geared toward the transformation of territory rather than the 'improvement' of populations, 2) discontinuous, dynamic and contested metabolic configurations of Southern cities, and 3) a strong co-constitution of political economy and materiality. It can be argued to what extent these tendencies are exclusive to "southern" cities and trying to describe "northern" cities through the lens of southern urbanism might be a fruitful endeavour for age-friendly cities as well.

\section{Acknowledgments}

This article is based upon work from COST Action CA15122 ROSEnet, supported by COST (European Cooperation in Science and Technology). COST is a funding agency for research and innovation networks. COST Actions help connect research initiatives across Europe and enable scientists to grow their ideas by sharing them with their peers. This boosts their research, careers, and innovation (www.cost.eu).

\section{Conflict of Interests}

The authors declare no conflict of interests.

\section{References}

Barron, A. (2015). Age-friendly seating \& sense of place. Manchester: WHO Global Network. Retrieved from https://www.whalleyrange.org/wp-content/ uploads/2016/07/Age-friendly-Seating-Report04.10.2015.pdf

Borraz, O., \& Le Galès, P. (2010). Urban governance in Europe: The Government of what? Métropoles, 7. Retrieved from http://journals.openedition.org/ metropoles/4297

Buffel, T. (2015). Researching age-friendly communities. Stories from older people as co-investigators. Manchester: Manchester University.

Buffel, T. (2019). Older coresearchers exploring agefriendly communities: An "insider" Perspective on the benefits and challenges of peer-research. The Gerontologist, 59(3), 538-548. https://doi.org/10. 1093/geront/gnx216

Buffel, T., Phillipson, C., \& Scharf, T. (2012). Ageing in urban environments: Developing "age-friendly" cities. Critical Social Policy, 32(4), 597-617.

Butler, J. (2004). Undoing gender. New York, NY: Routledge. 
de Certeau, M. (1984). The practice of everyday life. Berkeley, CA: University of California Press.

Équipe de Recherche MADA Québec, \& Carrefour Action Municipale et Famille. (2013). Guide d'accompagnement pour la réalisation de la démarche Municipalité amie des aînés [Toolkit for age-friendly municipality methodology]. Québec: Secrétariat aux aînés.

Finkelstein, R., Garcia, A., Netherland, J., \& Walker, J. (2008). Toward an age-friendly New York city: A findings report. New York, NY: New York Academy of Medicine.

Giacomini, A., \& Lefebvre, P.-O. (Eds.). (2019). Guide français des Villes Amies des Ainés [French toolkit for age friendly cities]. Paris: La Documentation française.

Goldman, L., Owusu, S., Smith, C., Martens, D., \& Lynch, M. (2016). Age-friendly New York city: A Case study. In T. Moulaert \& S. Garon (Eds.), Age-friendly cities in international comparison: Political lessons, scientific avenues and democratic issues (pp. 171-190). New York, NY: Springer.

Handler, S. (2014). A research \& evaluation framework for age-friendly cities. London: UK Urban Ageing Consortium.

Havighurst, R. J. (1954). Flexibility and the social roles of the retired. The American Journal of Sociology, 59(4), 309-311.

Houioux, G., \& Moulaert, T. (2017). 'Pour et par les aînés': Une méthode participative au service de l'entraide entre aînés. L'exemple de Mons Ville amie des aînés [For and by older people: A participatory methodology towards mutual aids between older people. The example of AFC Mons]. In A. Vandenhooft, S. Carbonnelle, T. Eggerickx, V. Flohimont, \& S. Perelman (Eds.), Vieillissement et entraide: Quelles méthodes pour décrire et en mesurer les enjeux? [Ageing and mutual aids: Which methods to describe and measure challenges?] (pp. 275-300). Namur: Presses Universitaires de Namur.

Keating, N., Eales, J., \& Phillips, J. E. (2013). Age-friendly rural communities: Conceptualizing "best-fit". Canadian Journal on Aging, 32(4), 319-332.

Lassen, A. J. (2015). Keeping disease at arm's length: How older Danish people distance disease through active ageing. Ageing and Society, 35(7), 1364-1383. https://doi.org/10.1017/S0144686X14000245

Lefebvre, H. (1991). The social production of space. Oxford: Blackwell.

Lefebvre, P.-O., \& Chapon, P.-M. (Eds.). (2014). Guide français des Villes Amies des Ainés. Bonnes pratiques à l'intention des acteurs locaux [French toolkit for age-friendly cities. Good practices for stakeholders]. Paris: La Documentation française.

Logan, J., \& Molotch, H. (1987). Urban fortunes. The political economy of place. Berkeley, CA: The University of California Press.

Löw, M. (2008). The constitution of space: The structura- tion of spaces through the simultaneity of effect and perception. European Journal of Social Theory, 11(1), 25-49.

Lui, C.-W., Everingham, J.-A., Warburton, J., Cuthill, M., \& Bartlett, H. (2009). What makes a community agefriendly: A review of international literature. Australasian Journal on Ageing, 28(3), 116-121.

Manchester City Council. (2009). Manchester: A great place to grow older. 2010-2002. Manchester: Joint Health Unit.

Moulaert, T., \& Biggs, S. (2013). International and European policy on work and retirement: Reinventing critical perspectives on active ageing and mature subjectivity. Human Relations, 1(66), 23-43. https://doi. org/10.1177/0018726711435180

Moulaert, T., \& Garon, S. (Eds.). (2016). Age-friendly cities in international comparison: Political lessons, scientific avenues, and democratic issues. New York, NY: Springer.

Moulaert, T., \& Houioux, G. (2016). A Belgian case study: Lack of age-friendly cities and communities knowledge and social participation practices in Wallonia. In T. Moulaert \& S. Garon (Eds.), Age-friendly cities and communities in international comparison: Political lessons, scientific avenues, and democratic issues (pp. 213-228). New York, NY: Springer.

Moulaert, T., Wanka, A., \& Drilling, M. (2018). The social production of age, space and exclusion: Towards a more theory-driven understanding of spatial exclusion mechanisms in later life. Sociální Studia/Social Studies, 15(1), 9-23. Retrieved from https://hal. archives-ouvertes.fr/hal-01895265

Müller, M. (2015). Assemblages and actor-networks: Rethinking socio-material power, politics and space. Geography Compass, 9(1), 27-41. https://doi.org/10. 1111/gec3.12192

New York City Office of the Mayor. (2013). 59 Initiatives age-friendly NYC: A progress report. New York, NY: New York City.

OECD. (2015). Ageing in cities. Paris: OECD Publishing.

Ouest-France. (2015, May 30). Public benches tested by the inhabitants. Ouest-France. Retrieved from https://www.ouest-france.fr/bretagne/rennes35000/les-bancs-publics-testes-par-les-habitants3443551

Plouffe, L., Kalache, A., \& Voelcker, I. (2016). A critical review of the WHO age-friendly cities methodology and its implementation. In T. Moulaert \& S. Garon (Eds.), Age-friendly cities and communities in international comparison (pp. 19-36). New York, NY: Springer.

Reckwitz, A. (2012). Affective spaces: A praxeological outlook. Rethinking History, 16(2), 241-258. https://doi. org/10.1080/13642529.2012.681193

São José, J. M. de, Timonen, V., Amado, C. A. F., \& Santos, S. P. (2017). A critique of the Active Ageing Index. Journal of Aging Studies, 40, 49-56. https://doi.org/ 10.1016/j.jaging.2017.01.001 
Schatzki, T. R. (1991). Spatial ontology and explanation. Annals of the Association of American Geographers, 81(4), 650-670. https://doi.org/10.1111/j. 1467-8306.1991.tb01713.x

Schindler, S. (2017). Towards a paradigm of Southern urbanism. City, 21(1), 47-64. https://doi.org/10.1080/ 13604813.2016.1263494

Sennett, R. (1999). The corrosion of character: The personal consequences of work in the new capitalism. New York, NY: Norton \& Company.

Stock Pictures. (2014). Sitting on one's haunches. Stock Pictures. Retrieved from http://www.stockpictures foreveryone.com/2014/07/sitting-on-oneshaunches.html

Stone, C. (1989). Regime politics, governing Atlanta, 1946-1988. Lawrence, KS: University Press of Kansas.

United Nations, Population Division. (2018). World urbanization prospects: The 2018 revision. New York, NY: United Nations.

Walsh, K., Scharf, T., \& Keating, N. (2017). Social exclusion of older persons: A scoping review and conceptual framework. European Journal of Ageing, 14(1), 81-98. https://doi.org/10.1007/s10433-016-0398-8

Wanka, A., Moulaert, T., \& Drilling, M. (2019). From environmental stress to spatial expulsion: Rethinking concepts of socio-spatial exclusion in later life. International Journal of Ageing and Later Life, 12(2), 1-27. https://doi.org/10.3384/ijal.1652-8670.18402

Wanka, A., Wiesböck, L., Allex, B., Mayrhuber, E. A.-S., Arnberger, A., Eder, R., . . . Kolland, F. (2018). Everyday discrimination in the neighbourhood: What a 'doing' perspective on age and ethnicity can offer. Ageing \& Society. https://doi.org/10.1017/ S0144686X18000466

WHO. (2007a). Global age-friendly cities: A guide. Geneva: WHO.

WHO. (2007b). Checklist of essential features of agefriendly cities. Geneva: WHO.

WHO. (2015). World report on ageing and health. Geneva: WHO.

WHO. (2018). The global network for age-friendly cities and communities: Looking back over the last decade, looking forward to the next. Geneva: WHO.

WHO. (2019). About the global network for agefriendly cities and communities. World Health Organization. Retrieved from https://extranet.who.int/ agefriendlyworld/who-network

WHO Global Database of Age-friendly Practices. (n.d.). Age-friendly world. World Health Organization. Retrieved from https://extranet.who.int/agefriendly world/search-afp/?_sfm_afp_start_date $=1974+2018$ \&_sfm_population $=0+110000000 \& \_s f m \_p r o p o r t i o n$ $=0+3615$

\section{About the Authors}
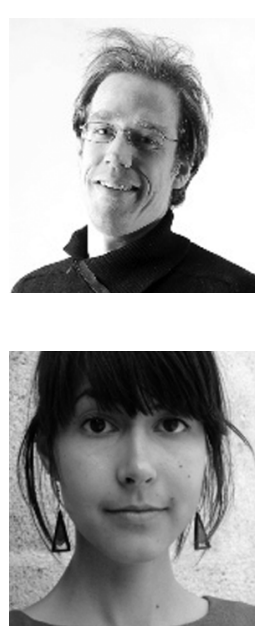

Thibauld Moulaert is Associate Professor at the University Grenoble Alpes, at the School of Political Studies and the PACTE Social Sciences Laboratory. His PhD research critically focuses on active ageing and employment; in his post-doc, it focuses on international discourses on ageing and, more recently, it concerns the relations between older people, citizenship, and environments and places.

Anna Wanka completed her PhD in Sociology in Vienna, 2016, titled Withdrawal from Public SpaceOlder Urban Residents and the Social Practices of Spatial (Dis-)Engagement. Her research foci lie within the sociology of ageing and social gerontology, particularly ageing and education, environmental gerontology and new technologies. Methodologically she specialises in mixed-methods research and holds expertise in both quantitative and qualitative methods. Today, her post-doc project "Doing Retiring-The Social Practices of Transiting into Retirement and the Distribution of Transitional Risks" at Goethe University Frankfurt on the main aims to advance praxeological life-course research. 


\section{Appendix}

\section{Five "Practices" that include benches and seats from the WHO Global Database of Age-friendly Practices (n.d.)}

\subsection{Testing urban furniture}

Status: Evaluated

Location: Rennes, France

Sectors: Urban development

Desired outcome for older people: Be mobile

“In its Actions plan, the Department of Older people of AFC Rennes decided on 29 May 2015 to invite older people and/or handicapped people to test a series of urban furniture in order to consider recommendations for choosing future benches and seats" (WHO Global Database of Age-friendly Practices, n.d.).

\subsection{Priority seats}

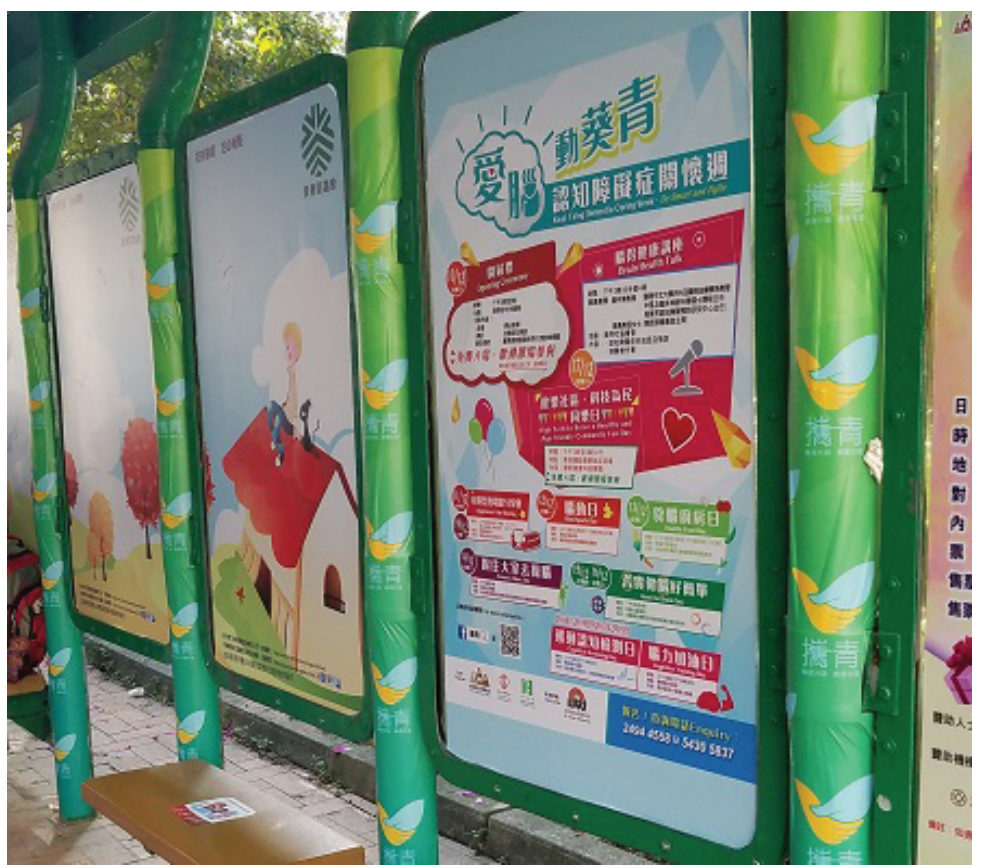

Figure A1. Priority seats at rain-shelters in Kwai Tsing District. Source: WHO Global Database of Age-friendly Practices (n.d.).

Location: Kwai Tsing District Hong Kong, China

Sectors: Urban development

Desired outcome for older people: Be mobile

Challenges: Physical constraints for the location of the benches, such as narrow pavement or the presence of footpaths were challenges during the project. The age-friendly ambassadors should bear these in mind when proposing suitable locations for such works.

From the WHO Global Database of Age-friendly Practices (n.d.) website:

The Age-Friendly Community Ambassadors (Kwai Tsing) (AFCAs-K\&T) carried out a community assessment project on Age-Friendly outdoor environment in Kwai Tsing in 2015. As of May 2016, there are 271 rain-shelters on pathways or footpaths in Kwai Tsing, but only 102 have seats installed. As such, AFCAs-K\&T suggested the Kwai Tsing District Council 
(K\&TDC) to install "priority seats" at rain-shelters on pavement or footpath in Kwai Tsing District. K\&TDC endorsed the plan in June 2016 and has earmarked funding in the 2016-17 financial year to undertake 16 projects to retrofit existing rain-shelters to provide seats. K\&TDC recognizes the need of older people and will continue to give priorities to similar proposals unless there is physical constraint found. AFCAs-K\&T's ultimate aim is to have seats installed at all rain-shelters, allowing older people to travel within the district with sufficient resting places. A public awareness and promotion program on priority seating for older people and people with needs will also be carried out. For example, a Youth Decoration and Design Competition on Priority Seats at Rain-shelters has been carried out in October 2016 to increase public awareness about Age-Friendly Environments.

\subsection{Installation of benches}

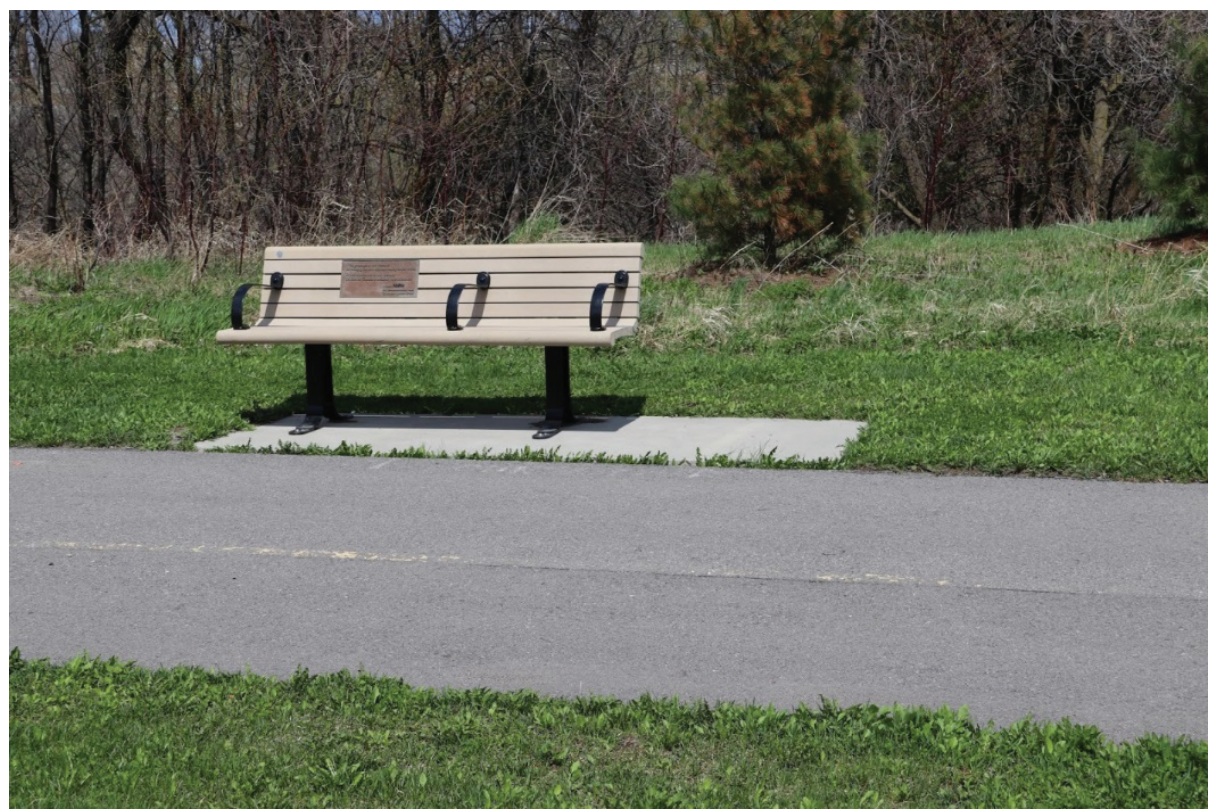

Figure A2. Bench installation in Ottawa. Canadian bench, similar to those presented in WHO Global Database of Agefriendly Practices (n.d.).

Started: 2012

Location: Ottawa, Canada

Desired outcome for older people: Be mobile

Sectors: Urban development

From the WHO Global Database of Age-friendly Practices (n.d.) website:

It can be difficult for many older adults to enjoy walking in Ottawa without somewhere to rest. The availability of seating areas was identified as one of the top urban age-friendly features for older people who participated in the Older Adult Plan consultations in 2011. As part of the Older Adult Plan, the City began installing additional benches on sidewalks in areas of the city with the highest concentrations of seniors (based on demographic data). In order to determine the most suitable locations for benches within these areas, the Infrastructure Services Department mapped amenities such as retirement and long term care residences, hospitals, shopping malls/grocery stores, and parks. For example, placing a bench mid-way between a retirement residence and a shopping mall was considered an optimal choice of location. A list of potential bench locations was then validated with a focus group of older adults. To date, the City has purchased and installed 34 additional benches at various locations across the city with high concentrations of seniors. The bench design meets accessibility standards in terms of height and arm rests. Installing additional seating across the city represents a simple initiative that supports seniors to go out, access services, and participate partake in walking and outdoor activities. 


\subsection{CityBench Program}

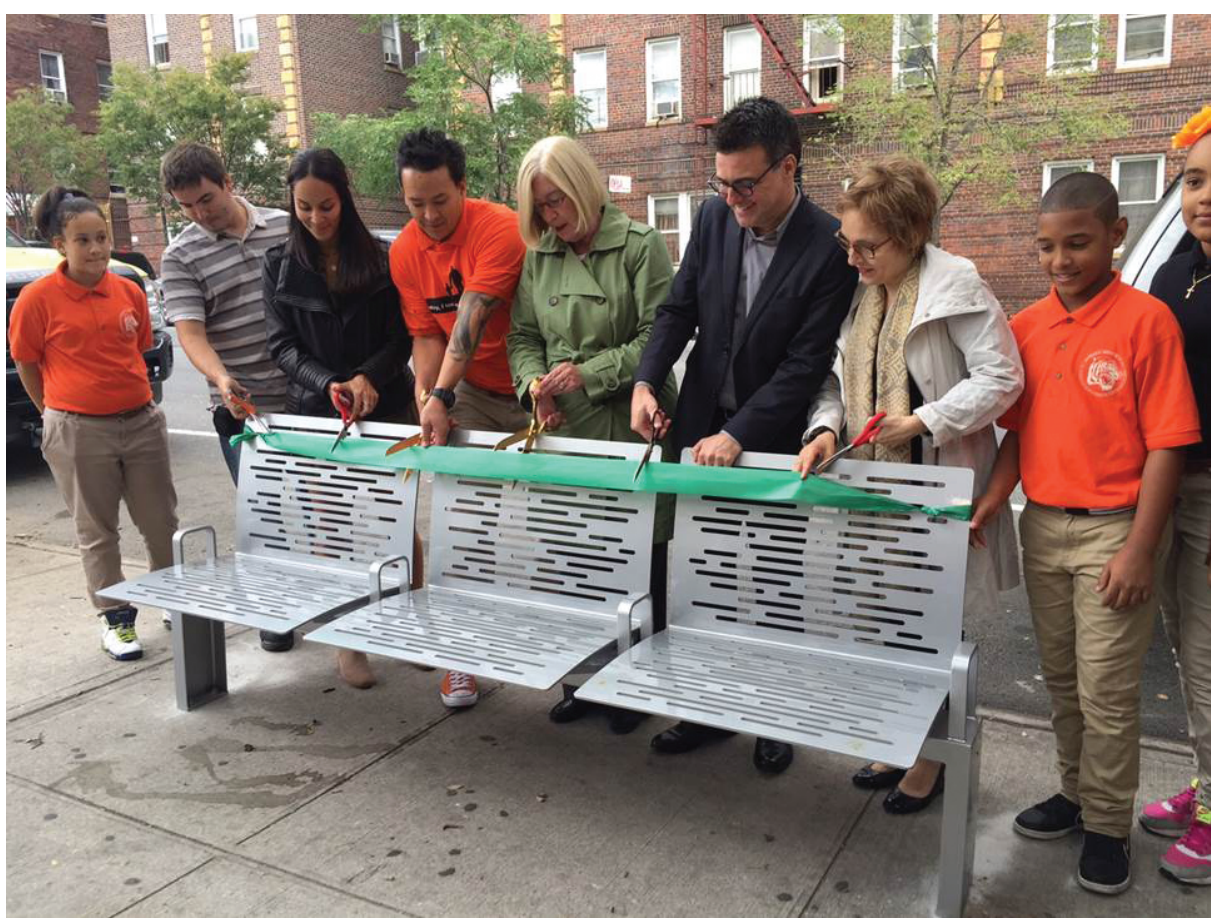

Figure A3. CityBench Program inauguration in New York. Source: Sayer (2015).

Status: Evaluated

Location: New York City, United States of America

Desired outcome for older people: Be mobile

Sectors: Urban development

From the WHO Global Database of Age-friendly Practices (n.d.) website:

The CityBench Program was created to increase the amount of public seating on New York City Streets. The 1500 benches are being installed around the City, particularly at bus stops, retail corridors, and areas with high concentrations of seniors. The installation process of the benches will be complete in 2015 and has already made streets more comfortable for transit pedestrians, especially older adults.

\subsection{Age-friendly parks checklist}

Location: London, Canada

Desired outcome for older people: Be mobile

Sectors: Urban development

From the WHO Global Database of Age-friendly Practices (n.d.) website:

In response the community priority of improving the age-friendliness of London parks, the Age Friendly London Network -Outdoor Spaces \& Buildings working group partnered with students at Western University to develop an Age Friendly Parks Checklist. The purpose of the checklist is to provide a standardized measurement of the amenities and conditions of London parks so that the working group could make informed recommendations on park upgrades and accessibility improvements. The students reviewed peer-reviewed and grey literature as well as examined Age Friendly Parks Checklists from other communities (most notably the Philadelphia Age Friendly Parks checklist) in order to identify the barriers and facilitators to park usage among older adults. Under the guidance of the Outdoor Spaces \& Buildings 
working group members, the students also conducted surveys with 89 older adults in London to gather information on park usage frequency and habits. The students and the working group members used this information to create an Age Friendly Parks checklist... with criteria that was specific and appropriate to London parks. The Western University students piloted the checklist by assessing 7 parks in the City. Then the Outdoor Spaces \& Buildings working group further refined the checklist and, with the help of city staff, have assessed a total of 377 parks in London to date. The checklist assesses the essential features that make a park accessible, welcoming, safe, and pleasant for an older adult or a person of any age to visit. These features include walkability, seating, access to washrooms, availability of water fountains, park amenities (e.g., presence of picnic tables, walking loops, community garden plots, etc.), signage, safety, and access to the park (i.e., presence of designated accessible parking spaces and pick up/drop off areas, proximity of bus routes, bike racks, etc.).

\section{References}

Sayer, J. (2015). Please be seated: New York City expands its CityBench program and grows 'street seat' parklets in Brooklyn. The Architects Newspaper. Retrieved from https://archpaper.com/2015/10/nyc-department-transport-receives-1-5million-expand-citybench-program

WHO Global Database of Age-friendly Practices. (n.d.). Age-friendly world. World Health Organization. Retrieved from https://extranet.who.int/agefriendlyworld/search-afp/?_sfm_afp_start_date $=1974+2018 \&$ _sfm_population=0+ $110000000 \& \_s f m \_p r o p o r t i o n=0+3615$ 